University of Nebraska - Lincoln

DigitalCommons@University of Nebraska - Lincoln

\title{
Progress in the development of a recombinant vaccine for human hookworm disease: The Human Hookworm Vaccine Initiative
}

\author{
Peter J. Hotez \\ The George Washington University, hotez@bcm.edu \\ Bin Zhan \\ The George Washington University \\ Jeffrey M. Bethony \\ The George Washington University \\ Alex Loukas \\ The George Washington University \\ Angela Williamson \\ The George Washington University \\ See nextpage for additional authors, \\ Part of the Chemical Engineering Commons
}

Hotez, Peter J.; Zhan, Bin; Bethony, Jeffrey M.; Loukas, Alex; Williamson, Angela; Goud, Gaddam Narsa; Hawdon, John M.; Dobardzic, Azra; Dobardzic, Reshad; Ghosh, Kashinath; Bottazzi, Maria Elena; Mendez, Susana; Zook, Bernard; Wang, Yan; Liu, Sen; Essiet-Gibson, Idong; Chung-Debose, Sophia; Xiao, Shuhua; Knox, David; Meagher, Michael; Inan, Mehmet; Correa-Oliviera, Rodrigo; Vilk, Paul; Shepherd, Herman R.; Brandt, Walter; and Russell, Philip K., "Progress in the development of a recombinant vaccine for human hookworm disease: The Human Hookworm Vaccine Initiative" (2003). Michael Meagher Publications. 1. https://digitalcommons.unl.edu/cbmemeagher/1

This Article is brought to you for free and open access by the Chemical and Biomolecular Research Papers -Faculty Authors Series at DigitalCommons@University of Nebraska - Lincoln. It has been accepted for inclusion in Michael Meagher Publications by an authorized administrator of DigitalCommons@University of Nebraska Lincoln. 


\section{Authors}

Peter J. Hotez, Bin Zhan, Jeffrey M. Bethony, Alex Loukas, Angela Williamson, Gaddam Narsa Goud, John M. Hawdon, Azra Dobardzic, Reshad Dobardzic, Kashinath Ghosh, Maria Elena Bottazzi, Susana Mendez, Bernard Zook, Yan Wang, Sen Liu, Idong Essiet-Gibson, Sophia Chung-Debose, Shuhua Xiao, David Knox, Michael Meagher, Mehmet Inan, Rodrigo Correa-Oliviera, Paul Vilk, Herman R. Shepherd, Walter Brandt, and Philip K. Russell 
Published in International Journal for Parasitology 33:11 (September 30, 2003), pp. 1245-1258; doi 10.1016/S0020-7519(03)00158-9 Copyright @ 2003 Australian Society for Parasitology Inc.

Published by Elsevier Science Ltd. Used by permission. http://www.parasitology-online.com

Submitted January 24, 2003; revised April 22, 2003; accepted May 19, 2003; published online August 1, 2003.

INVITED REVIEW

\title{
Progress in the development of a recombinant vaccine for human hookworm disease: The Human Hookworm Vaccine Initiative
}

\author{
Peter J. Hotez, ${ }^{\mathrm{a}, \mathrm{b}}$ Bin Zhan, ${ }^{\mathrm{a}}$ Jeffrey M. Bethony, ${ }^{\mathrm{a}, \mathrm{c}}$ Alex Loukas, ${ }^{\mathrm{a}}$ Angela Williamson, ${ }^{\mathrm{a}}$

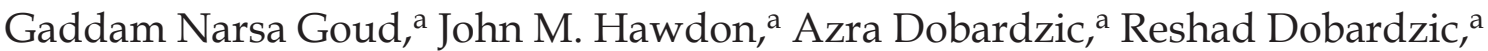

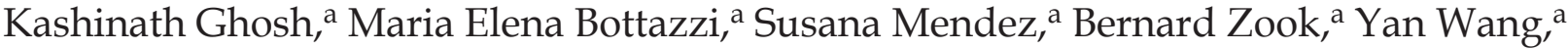 \\ Sen Liu, ${ }^{\text {a, d }}$ Idong Essiet-Gibson, ${ }^{a}$, Sophia Chung-Debose, ${ }^{a}$ Shuhua Xiao, ${ }^{d}$ David Knox, ${ }^{e}$ \\ Michael Meagher, ${ }^{\mathrm{f}}$ Mehmet Inan, ${ }^{\mathrm{f}}$ Rodrigo Correa-Oliveira, ${ }^{\mathrm{a}, \mathrm{c}}$ Paul Vilk, \\ Herman R. Shepherd, ${ }^{\mathrm{b}}$ Walter Brandt, ${ }^{\mathrm{b}}$ and Philip K. Russell ${ }^{\mathrm{b}}$ \\ a Department of Microbiology and Tropical Medicine, \\ The George Washington University, Washington, DC, USA \\ b Sabin Vaccine Institute, New Canaan, CT and Rockville, MD, USA \\ " Fundacion Oswaldo Cruz "Rene Rachou", Belo Horizonte, Brazil \\ ${ }^{\mathrm{d}}$ Institute of Parasitic Diseases, Chinese Center for Disease Control and Prevention, \\ Shanghai, People's Republic of China \\ e Moredun Institute, Edinburgh, UK \\ f Department of Chemical Engineering, University of Nebraska-Lincoln, Lincoln, NE, USA \\ Corresponding author - P. J. Hotez; tel 202 994-3532, fax 202 994-2913, email mtmpjh@gwumc.edu
}

\begin{abstract}
Hookworm infection is one of the most important parasitic infections of humans, possibly outranked only by malaria as a cause of misery and suffering. An estimated 1.2 billion people are infected with hookworm in areas of rural poverty in the tropics and subtropics. Epidemiological data collected in China, Southeast Asia, and Brazil indicate that, unlike other soil-transmitted helminth infections, the highest hookworm burdens typically occur in adult populations, including the elderly. Emerging data on the host cellular immune responses of chronically infected populations suggest that hookworms induce a state of host anergy and immune hyporesponsiveness. These features account for the high rates of hookworm reinfection following treatment with anthelminthic drugs and therefore, the failure of anthelminthics to control hookworm. Despite the inability of the human host to develop naturally acquired immune responses to hookworm, there is evidence for the feasibility of developing a vaccine based on the successes of immunizing laboratory animals with either attenuated larval vaccines or antigens extracted from the alimentary canal of adult blood-feeding stages. The major antigens associated with each of these larval and adult hookworm vaccines have been cloned and expressed in prokaryotic and eukaryotic systems. However, only eukaryotic expression systems (e.g., yeast, baculovirus, and insect cells) produce recombinant proteins that immunologically resemble the corresponding native antigens. A challenge for vaccinologists is to formulate selected eukaryotic antigens with appropriate adjuvants in order to elicit high antibody titers. In some cases, antigen-specific IgE responses are required to mediate protection. Another challenge will be to produce anti-hookworm vaccine antigens at high yield low cost suitable for immunizing large impoverished populations living in the developing nations of the tropics.
\end{abstract}

Keywords: Hookworm; Necator, Ancylostoma, vaccines, recombinant proteins, expression systems

\section{1. "The Great Infection of Mankind"}

The World Health Organization (WHO) estimates that approximately two billion people worldwide are infected with the soil-transmitted nematode helminths Ascaris lumbricoides, Trichuris trichirua, and the hookworms Necator americanus and Ancylostoma duodenale. Approximately
400 million of these infected individuals are children of school age and 300 million suffer from heavy worm burdens sufficient to result in severe disease. Overall, it is believed that, together with schistosomiasis, the soil-transmitted helminth infections account for $40 \%$ of the global morbidity caused by all infectious diseases, exclusive of malaria (WHO, 2000). 
Because they injure their human hosts directly by causing intestinal blood loss leading to iron deficiency and protein malnutrition, some investigators implicate hookworms as the most important helminthic cause of global disease burden. Professor Norman Stoll of the Rockefeller Institute and Foundation considered hookworms "The Great Infection of Mankind" (Stoll, 1962), second only to malaria as the major cause of human misery in the tropics.

Despite its global importance hookworm has, until recently, been overlooked as a public health problem. There are several reasons for this situation. Among them, hookworm disease and anemia, which result from parasiteinduced blood loss are frequently insidious and seldom dramatic in their clinical presentation; they are not usually associated directly with high mortality. Therefore, clinical experts often fail to link human hookworm infection to a significant cause of morbidity worldwide. Moreover, because of the misconception that hookworm could be prevented by increased use of shoes in tropical countries, hookworm was often not deemed worthy of scientific study. Possibly for these reasons, hookworm was not listed as one of the six major tropical infections of the Tropical Disease Research (TDR) program established by the WHO during the 1980s (Hotez et al., in press).

Our ignorance regarding the public health importance of hookworm began to change during the early 1990s when new quantitative estimates of disease burden based on the concept of disability adjusted life years (DALYs) revealed hookworm's global impact (Murray and Lopez, 1996). DALY estimates determined that the disease burden from hookworms exceeds three tropical infectious diseases under investigation in the WHO-TDR program: African trypanosomiasis, Chagas disease, and leprosy. Hookworm was also found to outrank dengue fever (Murray and Lopez, 1996).

More recent DALY estimates for the global burden of disease in 2001 indicate that hookworms cause even greater disease burden than previously believed (WHO, 2002). Hookworm exceeds conditions such as schistosomiasis and both hepatitis B and C. New data on the epidemiology of iron deficiency anemia in East Africa indicate that hookworm accounts for a large percentage of the huge DALY estimates resulting from this condition (Stoltzfus et al., 1997a; Stoltzfus et al., 1997b; Dreyfuss et al., 2000). Iron deficiency anemia currently accounts for a higher percentage of DALYs than HIV-AIDS and is almost as important as malaria! Hookworm-associated iron deficiency has been noted to be particularly common in coastal communities in the tropics (Lwambo et al., 1991). The observation that hookworm anemia occurs in an estimated 44 million women in pregnancy with resultant health consequences for the fetus and newborn (Bundy et al., 1995), will likely add to these disease burden estimates.

Newer findings that hookworms may induce a state of host immunological hyporesponsiveness (see below) and could promote susceptibility to intercurrent viral, bacterial or protozoan infections such as measles, HIV-AIDS (Borkow et al., 2000; Wolday et al., 2002) and tuberculosis (Borkow and Bentwich, 2000; Borkow et al., 2001) have tremendous importance in areas where these diseases overlap. High rates of hookworm are known to occur in Subsaharan Africa (Albonico et al., 1995; Behnke et al., 2000; Bradley et al., 1993; Brooker et al., 2000a; Brooker et al., 2000b; Lwambo et al., 1999; Palmer and Bundy, 1995; Partnership for Child Development, 1998; Stoltzfus et al., 2001; Stephenson et al., 1989), South China (Hotez et al., 1997; Liu et al., 1999; Zhan et al., 2000; Gandhi et al., 2001; Bethony et al., 2002; Hotez, 2002), Southeast Asia (Humphries et al., 1997), India and Nepal (Haswell-Elkins et al., 1988; Dreyfuss et al., 2000), and in the Americas (Bloch and Rivera, 1977; Labiano-Abello et al., 1999). In each of these regions HIV-AIDS is spreading rapidly. Therefore, a firm link between hookworm and HIV-AIDS would forever alter our concept of the importance of hookworm as a cause of global disease burden.

\section{The emerging epidemiology of hookworm}

Traditionally, the epidemiology of hookworm has been considered to be much like other soil-transmitted helminth infections, such as ascariasis and trichuriasis, i.e., an infection in which the heaviest worm burdens occur in children of school age (Bundy, 1990). Indeed, the clinical effects of pediatric hookworm anemia are well described in the literature (Hotez, 1989), including physical, mental and cognitive growth retardation effects (Smilie and Augustine, 1926; Hotez, 1989; Sakti et al., 1999; Beasley et al., 2002; Lwambo et al., 2000; Hotez, 2000; Stoltzfus et al., 2001).

While heavy hookworm burdens still occur among children in some tropical areas (Stephenson et al., 1989; Labiano-Abello et al., 1999), studies conducted worldwide within the last decade indicate that the peak prevalence and infection intensities for hookworm often occur in individuals in middle age, or even the elderly (Gandhi et al., 2001; Bethony et al., 2002). Shown in Figure 1 are the relationships between age and prevalence or age and intensity of hookworm in two different helminth-endemic regions of China (Hainan Province) and Brazil (Minas Gerias State). These represent areas of high hookworm transmission and endemicity (Gandhi et al., 2001; Bethony et al., 2002), and demonstrate that both prevalence and intensity increase as a function of age. Especially striking is the strong correlation $(r=0.69 ; P<0.001)$ between age and egg counts shown in Hainan. In the Hainan study, a variance components analysis revealed that age and gender made the most important contributions to infection intensity $(28-30 \%)$, with age alone responsible for $27 \%$ of this variation (Bethony et al., 2002). Figure 2 compares the age-related intensities of hookworm infections in both Hainan and Minas Gerias with other endemic helminth 

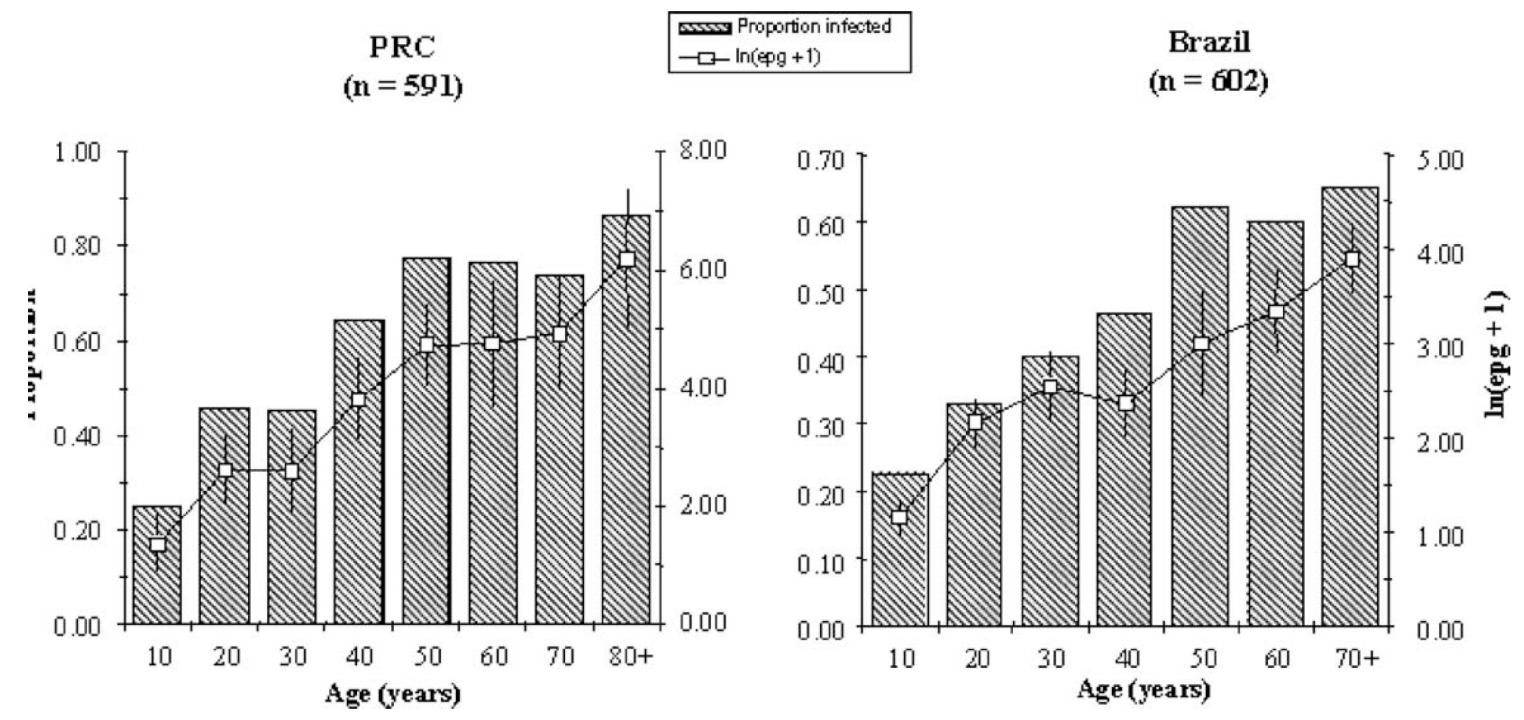

Figure 1. The prevalence and intensity of infection with Necator americanus increases with age in two endemic areas: Hainan Province, People's Republic of China (1999) and Minas Gerias, Brazil (2000). Data are from cross-sectional studies. Analysis of variance showed that egg counts were significantly different $(P<0.001)$ among the age intervals, and that the eldest four age intervals were significantly different $(P<0.05)$ from the younger age intervals, but not different from each other.

infections. In Hainan, Ascaris and Trichuris infections decrease after the age of 20, while in Minas Gerias the intensity of schistosomiasis diminishes after the age of 10 . This is in distinct contrast to hookworm epidemiologic patterns. Similar patterns for infection have been observed in other N. americanus endemic areas (Liu et al., 1999; Wang et al., 1999; Zhan et al., 2000; Humphries et al., 1997).

The association between increasing age and increasing prevalence and hookworm burden reveals an important public health problem for developing countries, since the elderly are seldom mentioned as a group either at high- risk for infection or the consequent morbidity associated with high worm burdens. The influence of aging on the prevalence and intensity of Necator infection has important public health consequences. In some parts of the developing world, such as China, the elderly are one of the most rapidly expanding age groups (Hotez, 2002).

The mechanisms by which hookworms establish chronic infections among the middle-aged and elderly are under active investigation. Increasing evidence suggests that this phenomenon may have an immunologic basis. In Papua New Guinea, Quinnell et al. $(1993,1995)$ observed

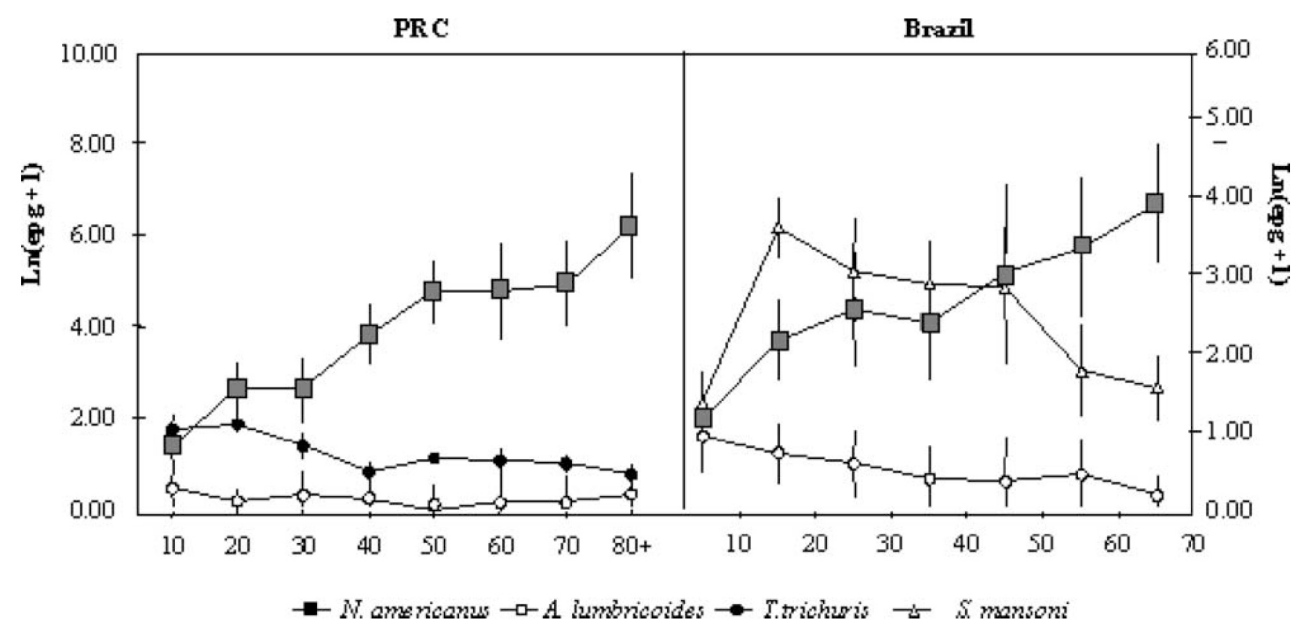

Figure 2. The age distribution of Necator americanus differs from other soil-transmitted helminths such as Ascaris lumbricoides, Trichuris trichiura, as well as Schistosoma mansoni. Panel A shows the relationship between age and infection intensity for three STHs in a cross-sectional study from Hainan, People's Republic of China. Ascaris lumbricoides and Trichuris trichiura epgs peak among children and then decline into adulthood. The intensity of infection with Necator americanus increases with age, peaking in eldest age category (80+). Panel B shows the distribution for Necator americanus in relation to other helminth infections, from Minas Gerais, Brazil. The distribution of Schistosoma mansoni infection intensity shows a traditional convex curve with age, increasing dramatically in young adults. The intensity of infection with Necator americanus again increases steadily with age, peaking in the eldest age categories. 
that experience with hookworm infection does not confer resistance, except in a selected few individuals who somehow acquire specific IgE responses against hookworm antigens (Pritchard and Walsh, 1995; Pritchard et al., 1995). Susceptibility to reinfection was confirmed among volunteers who remained susceptible to hookworm reinfection even after infecting themselves with $N$. americanus (Maxwell et al., 1987). In support of the inability of the human host to mount natural immunity to Necator infection is the preliminary observation that hookworm antigens may interfere with host lymphoproliferation and IL-4 levels during chronic infections (J. M. Bethony and M. E. Bottazzi, unpublished observations). This might even be an active immunosuppressive process that occurs through hookworm-derived secreted antigens. Several investigators have isolated and characterized hookworm macromolecules that interfere with host cellular immune responses (Moyle et al., 1994; Culley et al., 2000).

\section{Rationale for hookworm vaccine development}

The steady increase of hookworm burdens as a function of age and the apparent absence of naturally acquired immunity in endemic areas have serious implications for national and international control efforts. The public health control of hookworm and other soil-transmitted helminths currently relies heavily on the use of benzimidazole anthelminthic drugs, especially albendazole (Albonico et al., 1999). However, studies sponsored by the WHO and other organizations have shown that high rates of hookworm reinfection can occur within just a few months following benzimidazole treatments (Albonico et al., 1995). Presumably because of the absence of acquired immunity following natural infection, treated individuals remain susceptible to reinfection following exposure to third-stage infective hookworm larvae (L3) in the soil. This biological feature of the host-parasite relationship greatly limits the sustainability of anthelminthic chemotherapy-based control. In addition, most anthelminthic deworming programs worldwide currently target children in order to improve their physical growth, school performance, and cognitive development. While this approach might effectively, over time, reduce endemic exposure and worm burdens for Ascaris and Trichuris infections, there is no reason to believe that it would have an impact on endemic hookworm. It is therefore not surprising to discover that more than 1.2 billion individuals are infected with hookworms despite the widespread availability of albendazole.

An additional concern regarding the feasibility of sustainable control with benzimidazoles is the possibility of emerging anthelminthic drug resistance among human hookworm populations. In some nematode species benzimidazole resistance occurs secondary to the spread of a single point mutation in nematode tubulin alleles. This phenomenon has already resulted in widespread benzimidazole resistance among soil-transmitted helminths of ruminant livestock in the Southern Hemisphere (Conder and Campbell, 1995), and might partially account for an observed failure of mebendazole chemotherapy for human hookworm in southern Mali (De Clercq et al., 1997).

The unique epidemiology of hookworms resulting from their apparent immunosuppressive properties, together with the potential for emerging anthelminthic resistance, necessitates a search for alternative or complementary approaches to public health control that do not rely exclusively on anthelminthics. One approach for consideration is the development and use of anti-hookworm vaccines.

\section{Feasibility of hookworm vaccine development}

Is it feasible to develop a vaccine for an infection in which natural experience with the pathogen does not confer immunity? The concept of natural acquisition of immunity was, after all, the cornerstone for the development of first-generation attenuated vaccines against poliomyelitis, measles, and numerous other infections. A central challenge for hookworm vaccine development will be to stimulate an artificial immune response that is unique and results in disease burden reduction. In this sense, an antihookworm vaccine must overcome hurdles similar to those faced by vaccinologists who tackle HIV-AIDS and malaria.

Existing evidence that it is feasible to vaccinate against hookworms is based on three independent lines of research (Hotez et al., 1996, 1999, in press):

1. Studies first conducted in the Department of Helminthology at the Johns Hopkins School of Hygiene and Public Health during the 1930s in dogs and mice demonstrated that artificial immunity against challenge infections with Ancylostoma caninum L3 could be obtained by administering multiple inocula of living L3 either orally or subcutaneously (McCoy, 1931, Foster, 1935; Kerr, 1936; Otto and Kerr, 1939). The immunity conferred using multiple doses of living L3 was shown to be antibody mediated and could be administered passively (Otto, 1940, 1941). Typically, the immunity elicited by living L3 "vaccination" was not sterilizing but instead operated by reducing hookworm burdens relative to non-vaccinated control animals. The L3-vaccinated dogs were protected against hookworm disease characterized by heavy intestinal blood loss, but they were not protected against hookworm infection. Following very heavy challenge infections the mortality of severe hookworm disease was prevented by vaccination. Subsequent studies on the mechanisms of vaccine immunity demonstrated that host immune responses were directed primarily against the antigens secreted by L3 during host entry (Sarles, 1938; Taliaferro and Sarles, 1939; Sheldon and Groover, 1942).

2. Later, during the 1960s, the principles established by the development of living L3 vaccines were employed to develop an attenuated hookworm vaccine. This was 
accomplished by first damaging $A$. caninum L3 with ionizing radiation, including $X$-rays, gamma-rays and ultraviolet light (Miller, 1971, 1978, 1987). The irradiated L3 needed to remain viable in order for the vaccine to work-presumably viability was essential in order to ensure that the damaged L3 continued to secrete antigens after host entry. Ionizing radiation allowed the vaccinator to increase the dose of L3 used in an inoculum thereby decreasing the number of doses required to achieve effective immunity. Ultimately, an attenuated canine hookworm vaccine was developed and marketed first in Florida and later in the Eastern United States during the early 1970s (Miller, 1978). The product soon failed commercially, however, because of its high production costs, limited shelf-life viability and inability on the part of both pet owner and veterinarian to appreciate how a vaccine that does not elicit sterilizing immunity (i.e., does not prevent against hookworm infection) is still useful for protecting against hookworm disease.

3. Extracts of the esophagus of adult A. caninum elicit acquired immunity (Thorson, 1956). This parasite organ is enriched with proteases and much of the antibody in vaccinated dogs has the capacity to neutralize parasite protease activity (Thorson, 1956). These efforts confirmed a prediction first made by Asa Chandler during the 1930s that anti-enzyme antibodies have importance in mediating protective immunity against helminths (Chandler, 1932, 1936). More recently, studies conducted to develop a vaccine against Haemonchus contortus, a blood-feeding trichostrongyle nematode of sheep that is phylogenetically related to hookworms, identified the major antigens aligning the brush border membrane of the blood-feeding adult parasite alimentary canal (Knox, 2000). Among these antigens are parasite gut-derived glycoproteins that comprise a complex of proteases and other components (designated "H-gal-GP"), which bind to peanut lectin. Although the H-gal-GP complex is not ordinarily recognized during natural infection, and is considered a hidden antigen, the complex when administered with a saponin-derived adjuvant (Quil A) elicits high levels of vaccine protection with respect to adult worm burdens and fecundity (Knox and Smith, 2001).

To summarize, the feasibility of developing anti-hookworm vaccines is based on more than 70 years of successful protection in laboratory animals, which is elicited either by living L3 and their secreted antigens or by the antigens comprising the adult parasite alimentary canal.

\section{Hookworm antigen discovery and selection}

Hookworm antigens were selected as lead candidates for further testing on the basis of their link with either attenuated larval vaccines or the H-gal-GP complex.

\subsection{L3 secreted antigens}

Progress on attenuated hookworm larval vaccines pointed to the importance of secreted L3 antigens as the major immunogenic macromolecules associated with vaccine protection. However, it was found that A. caninum L3 constitutively release only trace amounts of protein (Hawdon et al., 1995). A major breakthrough was the observation that $\mathrm{L} 3$, stimulated at $37^{\circ} \mathrm{C}$ in the presence of a cocktail composed of an ultrafiltrate of canine serum and glutathione (or its derivatives), release comparatively large amounts of parasite-derived proteins (Hawdon and Hotez, 1996; Hawdon et al., 1995, 1996, 1999; Zhan et al., 2002a). This observation made it possible to isolate the major secreted L3 antigens, obtain partial amino acid sequences of the purified proteins, and subsequently clone and sequence their corresponding cDNAs.

\subsubsection{Ancylostoma secreted proteins}

The two most abundant gene products released by L3 under host-stimulatory conditions are cysteine-rich secretory proteins (CRISPs) belonging to the pathogenesis related protein (PRP) superfamily. The PRP superfamily is composed of a phylogenetically diverse array of animal and plant proteins including insect venom allergens, mammalian testis and epidydimal proteins, and plantpathogenesis related protein (Henriksen et al., 2001). The major L3 Ancylostoma secreted proteins (ASPs) are composed of ASP-2 (Hawdon et al., 1999), a $24 \mathrm{kDa}$ protein with a single PRP domain, and ASP-1 a $45 \mathrm{kDa}$ double PRP domain protein corresponding to a heterodimorphic repeat (Hawdon et al., 1996). Isolation of approximately 100 pmoles of each protein required the collection of up to 300,000 A. caninum L3, which were obtained by coproculture from the feces of infected donor dogs. This was followed by partial amino acid sequencing of the purified protein and then the synthesis of degenerate oligonucleotides for cDNA library screening (Hawdon et al., 1996, 1999). Orthologues of both asp-1 and asp-2 cDNAs were also subsequently isolated and cloned from $A$. duodenale, Ancylostoma ceylancium and N. americanus (Zhan et al., 1999). The orthologues exhibit high degrees of amino acid sequence similarity to each other. For instance, the $N$. americanus ASP-1 (Na-ASP-1) exhibits 97\% identity to A. caninum ASP-1 (Ac-ASP-1).

The biological function of the ASPs is not known. One study conducted with an ASP orthologue from Onchocerca volvulus suggests that it may exhibit angiogenic properties (Tawe et al., 2000). However, ASP orthologues are also present in the free-living nematode Caenorhabditis elegans and the plant pathogen Meloidogyne incognita, and therefore also presumably have a function that is unrelated to the host-parasite relationship. Adult hookworms also produce single and double domain ASPs, which immunolocalize to a number of different nematode organs including the cuticle, cephalic glands, and the brush border of the alimentary canal (Zhan et al., 2003). 
There are several lines of evidence that point to the ASPs as promising vaccine candidates: (1) Natural product single and double domain ASPs were shown to protect sheep and guinea pigs against challenge infections with H. contortus (Kooyman et al., 2000; Sharp et al., 1992; Sharp and Wagland, 1998; Schallig et al., 1997a, 1997b, 1997c). Vaccine protection relies on the presence of high levels of anti-ASP IgE (Kooyman et al., 2000). (2) Antibodies obtained from the abomasal mucus and draining lymph nodes from calves immunized with multiple infections of Ostertagia ostertagi recognize an ASP orthologue (De Maere et al., 2002). In addition fractions of helminth antigens that protect cattle against $O$. ostertagi infection are enriched in single domain ASPs (Geldhof et al., 2003). (3) Vaccination of mice with a recombinant Escherichia coli fusion protein composed of a polyhistidine tag and amino acids 96-424 of either Ac-ASP-1 or Na-ASP-1 results in host immune responses, which inhibit the extra-intestinal migration of A. caninum L3 into the lungs following oral infection (Ghosh et al., 1996; Ghosh and Hotez, 1999; Liu et al., 2000). Anti-Ac-ASP-1 antibody also passively protects against larval migration (Ghosh and Hotez, 1999). (4) In two cross-sectional epidemiologic studies it was determined that residents of Hainan Province, China and Minas Gerais State, Brazil who harbor less intense hookworm burdens (as measured by quantitative egg counts) exhibit high titers of circulating antibodies against a single domain ASP from L3 (Jeff Bethony, unpublished observation).

\subsubsection{Astacin-like metalloprotease (MTP)}

Hookworm L3 also releases a $62 \mathrm{kDa}$ zinc metalloprotease upon host-stimulation (Zhan et al., 2002a). The MTP1 enzyme is of the astacin class represented by a metalloprotease from the crayfish Astacus astacus. In addition to a catalytic domain composed of zinc in the enzyme active site coordinated by the imidazoles of conserved histidine residues, MTP-1 also contains an epidermal growth factor domain of unknown function. MTP-1 is an immunodominant protein and was first cloned and isolated by screening an A. caninum cDNA expression library with pooled sera from hookworm-infected individuals who harbor low worm burdens and are putatively resistant (Zhan et al., 2002a). Calves immunized with O. ostertagi L3 also recognize an MTP-1 orthologue (De Maere et al., 2002). Studies examining the vaccine potential of Ac-MTP-1 from $A$. caninum are under evaluation, as is an orthologue from Ancylostoma ceylanicum (see below).

\subsubsection{Other L3 antigens}

In addition to the ASPs and MTP-1, Ancylostoma L3 also releases macromolecules with amino acid similarities to a $60 \mathrm{kDa}$ acetylcholinesterase $(\mathrm{ACH})$ and a $16 \mathrm{kDa}$ (144 amino acids) putative transthyreitin (TTR), which may bind retinol binding proteins (Hawdon et al., un- published). Previously, a secreted acetylcholinesterase has shown promise as a vaccine target against Dictyocaulus viviparous (McKeand, 2000) and Trichostrongylus colubriformis (Griffiths and Pritchard, 1994). Each of these proteins is being evaluated as vaccine candidates, as is a hookworm L3 surface protein similar to Ov-103 from $O$. volvulus.

\subsection{Adult hookworm antigens}

\subsubsection{Secreted antigens}

There is no evidence that the excretory-secretory proteins released by adult hookworms elicit high levels of vaccine protection. The major protein secreted by adult hookworms is TMP, a $16 \mathrm{kDa}$ orthologue of mammalian tissue inhibitor of metalloprotease (Zhan et al., 2002b). AcTMP comprises almost $10 \%$ of the protein secreted in vitro by adult $A$. caninum (Zhan et al., 2002b). The function of this molecule for adult hookworms at the site of attachment in the mammalian intestine is unknown. However, of interest is the observation that regions of amino acid sequence similarity between Ac-TMP and mammalian TIMPs are not those predicted to be in contact with their target matrix metalloproteases (Zhan et al., 2002b). This suggests the possibility that Ac-TMP has a function other than metalloprotease inhibition. In addition to TMP, adult A. caninum hookworms also release serine protease inhibitors including those involved in the coagulation cascade such as factor Xa (Cappello et al., 1995, 1996) and VIIa-tissue factor (Stanssens et al., 1996), and some adult-specific ASPs (Zhan et al., in press).

\subsubsection{H-gal-GP orthologues}

The H-gal-GP complex from the brush border of the alimentary canal of $H$. contortus is composed of multiple components including a metalloendopeptidase of the neprilysin family, an aspartic protease, a cysteinyl protease, a cystatin, a thrombospondin orthologue, and a galectin (Knox, 2000). As noted above, the complex elicits high levels of protection against $H$. contortus challenge infections in sheep (Knox, 2000; Knox and Smith, 2001), although each component has so far not been examined individually as a natural product. Orthologues of each of the protease components of the complex have been cloned from hookworms including A. caninum-metalloendopeptidase1 (Ac-MEP-1) (Jones and Hotez, 2001), A. caninum-cysteinyl proteases (Ac-CP-1 and Ac-CP-2) (Harrop et al., 1995; Loukas et al., 2000), and A. caninum-aspartic proteases (Ac-APR-1 and Ac-APR-2) (Harrop et al., 1996; Williamson et al., 2002, 2003a, 2003b). Immunolocalization studies confirm that some of these proteases align the brush border membrane of the alimentary canal of adult hookworms ( Figure 3). These proteases are believed to operate in a coordinated fashion to facilitate host hemoglobin degradation during blood feeding (Brinkworth et al., 2000, 2001). 


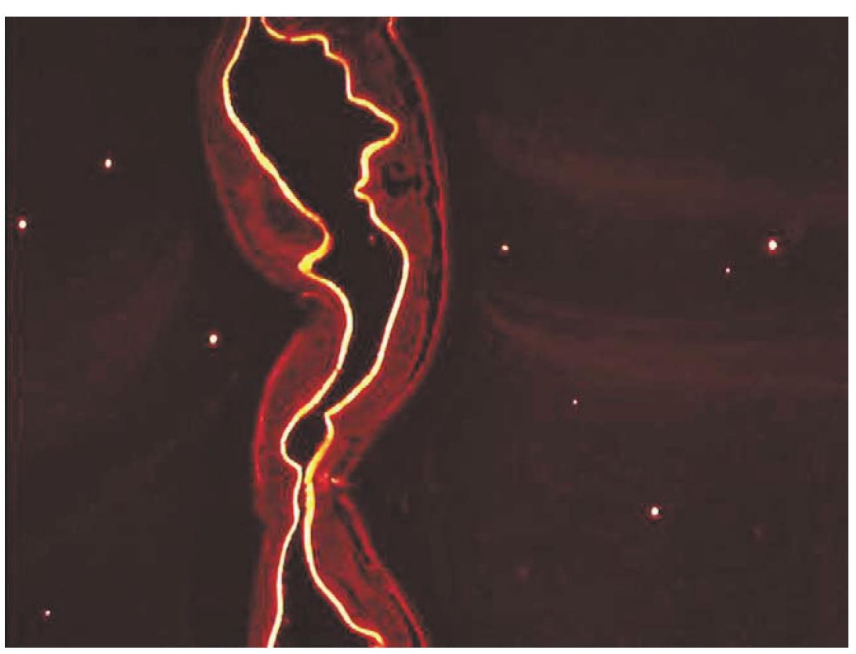

Figure 3. Immunolocalization of Ac-MEP-1 (neprilysin-like adult hookworm metalloprotease) to the brush border membrane of the adult hookworm alimentary canal.

\section{The rules of engagement}

Work conducted during the decade of the 1990s on H. contortus vaccine protection experiments in sheep and A. caninum vaccine protection experiments in mice has provided some useful paradigms that might be applicable to preclinical vaccine protection experiments in laboratory animals.

1. Many of the candidate vaccine antigens under evaluation are hydrolytic enzymes, including proteases and acetylcholinesterases from L3 and adult stages. While the natural products isolated from parasites typically maintain their enzymatic activity, the activity is lost when the protease cDNAs are expressed in E. coli. Therefore, expression of bioactive molecules usually requires eukaryotic vectors.

2. Similarly, in instances where natural product antigens protect against challenge infections, the corresponding recombinant protein expressed in E. coli fails to reproduce the protection. In most cases this is because the conformational epitopes are lost during E. coli expression. Incorrect disulphide bond formation probably accounts for most of the lost epitope expression, particularly for cysteine-rich proteins like the ASPs, rather than the absence of correct glycosylation. The failure of E. coli to produce correctly folded antigens for vaccination was observed for L3 ASPs from H. contortus (Sharp and Wagland, 1998) and A. caninum (see below), and for the $\mathrm{H}-$ gal-GP complex components (Knox and Smith, 2001).

3 . In some cases eukaryotic expression restores the conformational epitopes lost during E. coli expression. This has been demonstrated for baculovirus expressed ASP from H. contortus (Sharp and Wagland, 1998) and yeast-expressed Ac-ASP-1 (see below).

4. Among the eukaryotic vectors that have been employed to express candidate nematode vaccine anti- gens are baculovirus, insect cells, and yeast. To date, it has not been possible to predict which vector system will work best. However, baculovirus and insect cells will likely prove to be too expensive for the manufacture of a public sector hookworm vaccine. Leading the yeast expression vectors is the methanol-utilizing organism Pichia pastoris, which produces proteins in high yields and is relatively inexpensive compared to other eukaryotic expression systems.

5. In the few studies that have attempted to define the mechanisms associated with vaccine protection, achieving high levels of host antibody is required for reduction in worm burdens (Ghosh and Hotez, 1999). In some cases host IgE may be the principal effector antibody. This was suggested by the finding that low H. contortus worm burdens in sheep associated with high levels of IgE directed H. contortus ASP (Kooyman et al., 2000). The importance of $\mathrm{IgE}$ antibody is also underscored by preliminary epidemiologic data suggesting that host IgE directed against ASP-2 was associated with reduced hookworm intensity, as determined by quantitative egg counts (Jeff Bethony, unpublished data).

6. Achieving high levels of host antibody using baculovirus, insect cell, or yeast-expressed proteins will be challenging, particularly when these proteins are formulated with aluminum-based adjuvants such as alum or alhydrogel. The requirement for high levels of immunogenicity has prompted the search for alternative adjuvants.

\section{Hookworm antigen expression}

Over the last 2 years, focused efforts have been made to express the lead candidate antigens in both prokaryotic and eukaryotic systems (Table 1).

\subsection{L3 hookworm antigens}

Expression of Na-asp-1, Ac-asp-2, and Ac-mtp-1 cDNAs in $E$. coli has so far produced recombinant fusion proteins containing polyhistidine tags, which are neither soluble nor correctly refold in the absence of harsh denaturants, including ionic detergents. In addition, the E. coli recombinant fusion proteins frequently are expressed in inclusion bodies that are heavily contaminated with other bacterial constituents. Frequently it is not possible to separate the recombinant fusion proteins away from these contaminants. In the case of the ASPs, the high number cysteines (10 in ASP-2 and 20 ASP-1) presumably cause recombinant polypeptides to form with aberrant disulphide bond formation. Recombinant E. coli Na-ASP-1 does not exhibit conformational epitopes corresponding to the native protein. As shown in Figure 4, polyclonal antibodies prepared against $E$. coli Na-ASP-1 fail to immunoprecipitate the corresponding native protein from soluble L3 extracts. Similarly, recombinant Ac-MTP-1 expressed in E. 
Table 1. Lead candidate hookworm vaccine antigens

\begin{tabular}{|c|c|c|c|}
\hline Antigen & Description & MW (kDa) & Expression vector \\
\hline \multicolumn{4}{|c|}{ L3 secreted antigens } \\
\hline ASP-1 & Pathogenesis-related protein & 45 & Pichia pastoris \\
\hline MTP-1 & Astacin metalloprotease & 62 & Baculovirus \\
\hline TTR & Transthyreitin & 16 & Escherichia coli and P. pastoris \\
\hline $\mathrm{ACH}$ & Acetylcholinesterase & 60 & P.pastoris \\
\hline MEP-1 & Neprilysin metalloprotease & 99 & Insect cells \\
\hline APR-2 & Aspartic protease & 45 & Baculovirus \\
\hline $\mathrm{CP}-1$ & Cysteinyl protease & 35 & Insect cells and $P$. pastoris \\
\hline $\mathrm{CP}-2$ & Cysteinyl protease & 35 & P. pastoris \\
\hline ASP-5 & Pathogenesis-related protein & 24 & P. pastoris (pending) \\
\hline
\end{tabular}

coli does not exhibit enzymatic activity. In order to overcome these hurdles and express recombinant proteins either having catalytic activity or appropriate conformational epitopes, their corresponding cDNAs had to be re-engineered in eukaryotic vectors, including baculovirus, insect cells, or yeast. Polyclonal antibodies prepared against $P$. pastoris expressed Na-ASP-1 immunoprecipitate the native protein from soluble L3 extracts (Figure 4). To date, the following L3 recombinant proteins have been successfully expressed in P. pastoris: Na-ASP-1, NaASP-2, and Ac-TTR, from N. americanus and A. caninum, respectively, as well as Ay-ASP-1 and Ay-ASP-2, the orthologues from $A$. ceylanicum. One of the L3 acetylcholinesterases has also been expressed (M. Selkirk, personal communication). To date it has not been possible to express soluble Ac-MTP-1 and Ac-ASP-2 in yeast. However, Ac-ASP-2 as well as catalytically active Ac-MTP-1 was recently expressed in baculovirus.

\subsection{Adult hookworm antigens}

Two of the small protease inhibitors released by adult A. caninum hookworms, Ac-TMP and Ac-AP (factor Xa inhibitor anticoagulant peptide) have been expressed as soluble recombinant fusion proteins in E. coli. However, none of the H-gal-GP orthologous proteases expressed in E. coli are soluble or exhibit enzymatic activity. Ac-MEP1, Ac-CP-1, a cysteinyl protease, and the aspartic proteases, in contrast have been expressed as bioactive, soluble enzymes in either viral or non-viral insect cell expression systems (Loukas, Williamson, et al., unpublished). Ac-CP2 has been expressed in P. pastoris in biologically active form. Work is in progress to express the adult-stage-specific ASPs in eukaryotic systems (Zhan et al., in press).

\section{Hookworm antigen-adjuvant formulation and vaccine testing}

Two laboratory animal systems are now in routine use for preclinical vaccine development: hamsters challenged with L3 of A. ceylanicum and dogs challenged with L3 of A. caninum. An advantage of the hamster model is its relatively low cost compared to dogs. In addition, hamsters infected with $A$. ceylanicum experience weight and blood loss similar to human disease from heavy infections (Bungiro et al., 2001). However, A. ceylanicum does not ordinarily cause intestinal blood loss in humans and the hamster is not a natural host for the parasite. In addition, the number of adult hookworms that establish in hamsters is low - this requires the use of large numbers of hamsters in order to achieve adequate sample sizes for comparing experimental and control groups. In contrast, dogs are the natural hosts of $A$. caninum, and this model closely resembles $A$. duodenale hookworm infection. The ability to achieve high adult worm burdens in the laboratory

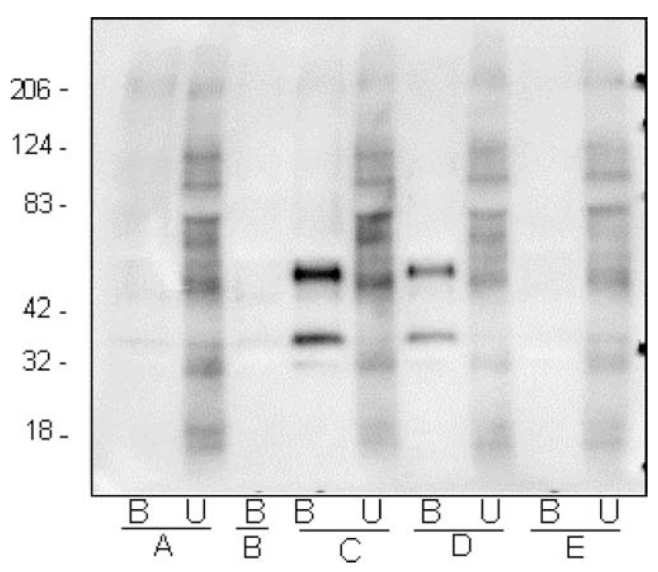

Figure 4. Immunoprecipitation of Ac-ASP-1 from biotinylated extracts of A. caninum L3. B, protein bound to strepavidin resin (immunoprecipitated). U, protein unbound to strepavidin resin (non-immunoprecipitated). Group A, canine antiserum to two doses of irradiated A. caninum L3. Group B, canine antiserum to alum (adjuvant control). Group C, canine antiserum to Na-ASP-1 expressed in Pichia pastoris and administered with alum in four doses separated by 3 weeks. Group D, canine antiserum to Na-ASP-1 expressed in Pichia pastoris and administered with alum in four doses on days 1, 4, 60, and 64 . Group E, canine antiserum to Na-ASP-1 expressed in Escherichia coli and administered with alum in four doses on days 1, 4, 60, and 64 . 

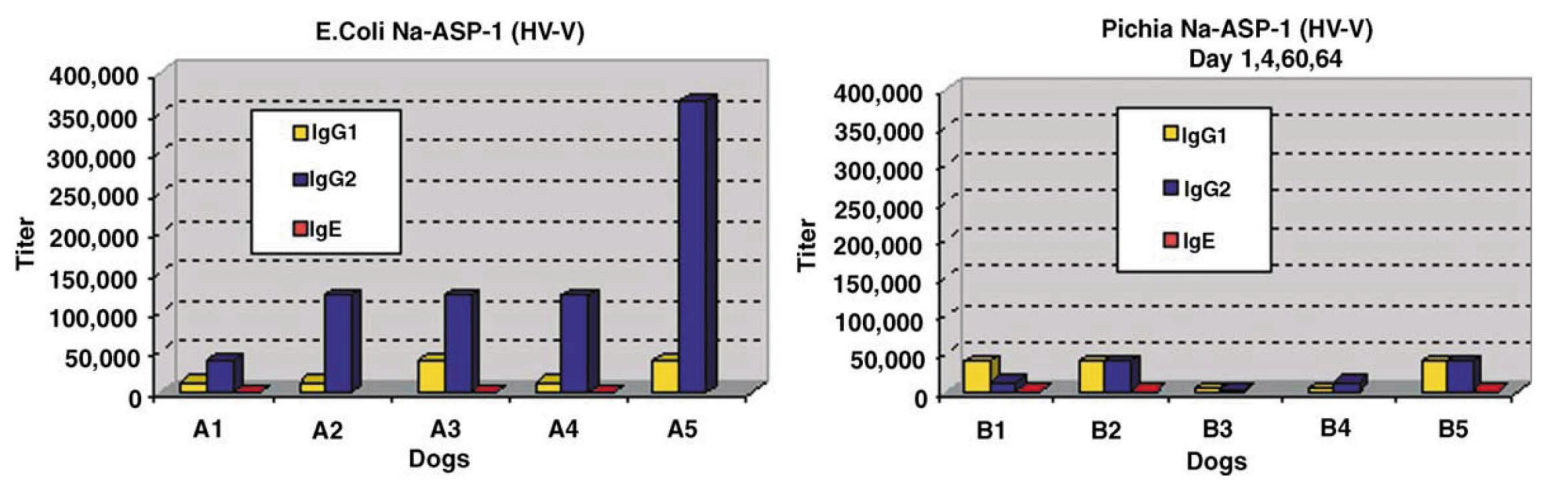

Figure 5. Comparison of antigen-specific IgG1, IgG2, and IgE canine antibody titers in purpose-bred beagle dogs ( $n=5$ per group) vaccinated with $150 \mu \mathrm{g}$ of Escherichia coli Na-ASP-1 (four doses) or Pichia pastoris Na-ASP-1 (four doses using two different schedules). An additional group of dogs $(n=5)$ was vaccinated with $A$. caninum irradiated L3 (two doses).

reduces the sample size required for comparing experimental and control groups. For vaccine studies, purposebred beagles are usually vaccinated with hookworm antigens formulated with adjuvants beginning at 8-10 weeks of age. Up to 2 months are usually required to complete the immunization series, followed by challenge infections (Hotez et al., 2002).

In addition to the two Ancylostoma systems under investigation, some efforts have been made to adapt $N$. americanus to laboratory hamsters. Recently, Xiao Shuhua and his colleagues adapted $N$. americanus by passing it through 100 generations in a Chinese strain of the golden hamster (Xue et al., in press). By doing so, they have obviated the requirement for exogenous steroids and can obtain reasonable levels of adult hookworm burdens by infecting hamsters at 9-10 weeks of age. In contrast, other investigators have had to rely on infecting neonatal hamsters (Behnke and Pritchard, 1987).

To date, studies in dogs and hamsters have revealed that E. coli recombinant fusion proteins are more immunogenic than recombinant proteins expressed in baculovirus, insect cells, or yeast. Shown in Figure 5 is a direct comparison of pre-challenge antibody titers in dogs (five per group) vaccinated either with E. coli Na-ASP-1 or P. pastoris Na-ASP-1 formulated with alhydrogel. The former exhibits far higher IgG2 antibody titers, although the IgG1 and IgE responses are similar. However, it is not clear whether the IgG2 responses might be directed against bacterial lipopolysaccharide or E. coli protein contaminants. As noted above (Figure 4), many of the peptide sequences recognized by canine anti-E. coli-Na-ASP-1 do not correspond to conformational epitopes on the native protein.

The comparatively low immunogenicity of eukaryotic recombinant hookworm antigens formulated with aluminum-based adjuvants (e.g., alum and alhydrogel) points out a new requirement to explore alternative adjuvants. Among those under investigation, are oil-water emulsions such as montanide ISA-720 (Seppic) and ASO3 (GlaxoSmithKline), as well as adjuvants containing saponin derivatives such as ASO2 (GlaxoSmithKline) and Quil A. ASO2 is an oil-water emulsion that contains QS-
21 (derived from saponin) and a lipid A derivative. Both ISA-720 and ASO2 have been used successfully in human clinical trials (Bojang et al., 2001; Doherty et al., 1999).

The importance of eliciting strong immune responses against the candidate recombinant hookworm antigens is highlighted by studies, which examine the relationship between antibody titers and hookworm burdens. As shown in Figure 6, high levels of antigen-specific IgE directed against recombinant $E$. coli Na-ASP-1 and Ac-TTR inversely correlate with hookworm burdens. In the case of E. coli Ac-MTP-1, the inverse relationship between antibody titer and worm burden is best correlated with IgG2 (Figure 6). Because many of these antibodies directed against these E. coli proteins probably do not recognize conformational epitopes, the levels of vaccine protection should improve significantly by employing recombinant antigens expressed in eukaryotic systems. Also of great promise is the exploitation of new platform technologies for the development of anti-hookworm vaccines, including the use of hepatitis B core particles for the expression of peptide epitopes from candidate vaccine antigens (Birkett et al., 2002). Among them are amino acids 291303 of Na-ASP-1, which correspond to a predicted hydrophilic loop in the native molecule.

To summarize, each of the lead antigens has been expressed in eukaryotic vectors and is now under evaluation as candidate vaccines in one or more of three different laboratory animal challenge models $(A$. caninum in dogs, A. ceylanicum in hamsters and $N$. americanus in hamsters). Results from these studies will provide the basis for up-selection leading to process development and pilot manufacture.

\section{Future prospects}

Even after process development and pilot manufacture is completed, however, there are still a number of hurdles that must be overcome before an anti-hookworm vaccine is produced for the developing world. Among them are the following. 
1. No human clinical trials have ever been conducted with a recombinant nematode vaccine.

2. Preliminary studies conducted in Brazil suggest that patients chronically infected with hookworm are functionally immunosuppressed and do not develop lymphoproliferative responses to hookworm antigens (J. Bethony and M. E. Bottazzi, unpublished observations). However, some patients who are treated for hookworm with anthelminthic drugs acquire a renewed capacity to respond to hookworm antigens. This suggests that human anti-hookworm vaccinations may need to be preceded by an initial round of anthelminthic treatment.

3. Little is known on the role of cross reactivity and regulation of the immune response in individuals carrying more than a single helminthic infection, or its correlation with the development of resistance to infection and reinfection.

4. If the requirement to develop IgE responses against some of the lead candidate hookworm vaccine antigens is confirmed, then it may become necessary to choose adjuvant formulations and doses designed to enhance allergic-type responses. This could contribute to the vaccine's ultimate toxicity.

5. Many of the hookworm antigens selected for further development contain partial amino acid sequences that are homologous with mammalian proteins. The potential for cross reactivity to autoantigens require investigation.

6. Hookworm is a disease of the "poorest of the poor" in the developing nations of the tropics. For this reason, there is practically no commercial market for an antihookworm vaccine. The institutions for developing and manufacturing public sector vaccines are still rudimentary. This is particularly unfortunate, given that the next generation of vaccines for diseases in developing countries, e.g., hookworm, HIV-AIDS, malaria, will require high levels of technological sophistication (Hotez, 2001; Broder et al., 2002).

7. Immunity to hookworm vaccines must be long-lasting in order to protect at-risk individuals exposed to hookworm L3 in adulthood.

8. The geographic variation of the candidate hookworm antigen amino acid sequences is largely unknown. However, preliminary studies with Na-ASP-1 indicate that for this particular antigen, geographic variation is not significant (J. Hawdon, unpublished observation).

Despite these obstacles, the potential impact of developing a hookworm vaccine is huge. Because of its contribution to the burden of disease caused by iron deficiency anemia, hookworm is arguably the most significant human helminth pathogen worldwide. Its possible role in promoting increased susceptibility to other intercurrent pathogens, including HIV-AIDS will ensure hookworm's disease burden impact.
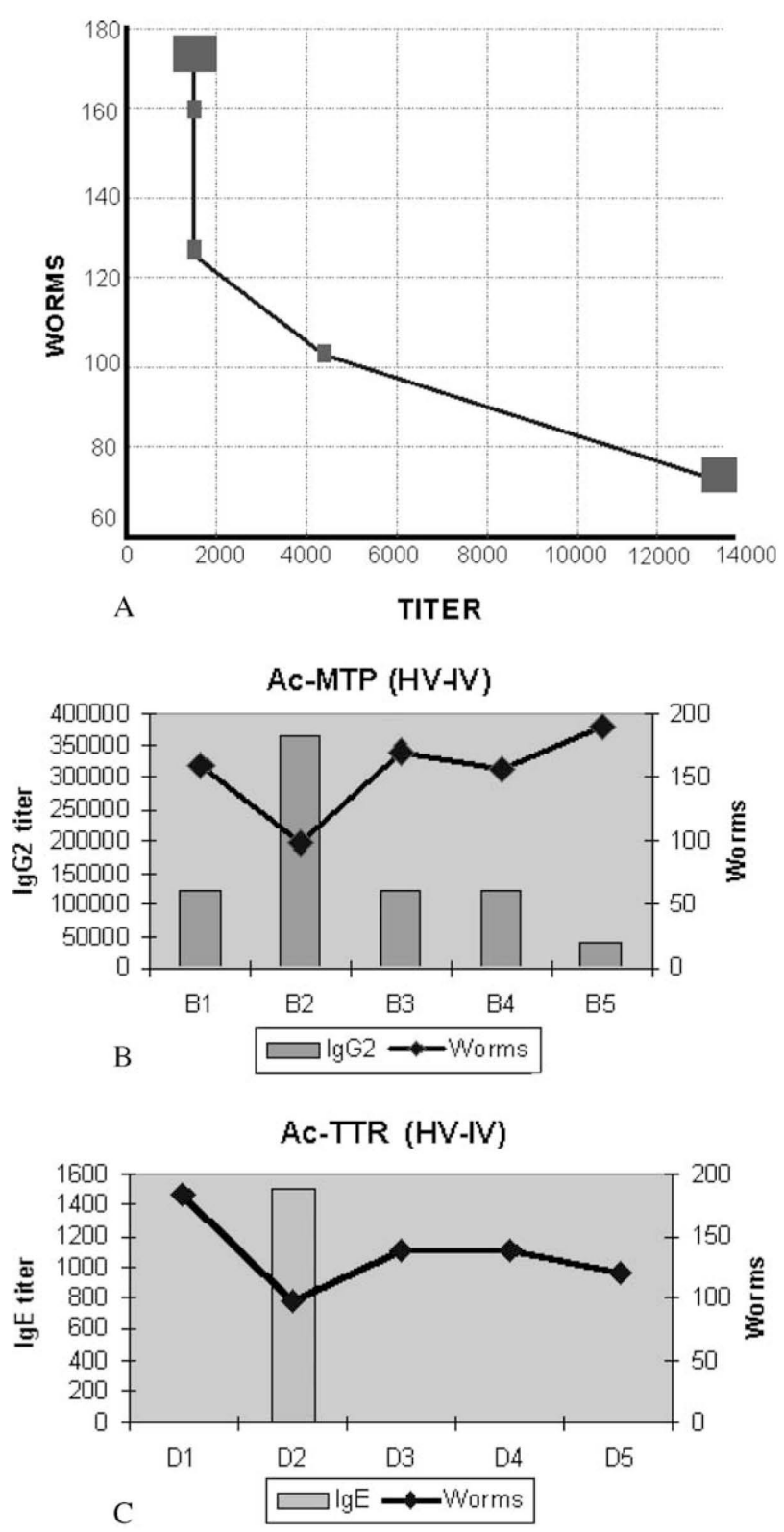

Figure 6. Inverse relationships of antibody titers to Escherichia coli expressed recombinant fusion proteins to hookworm burden in vaccinated dogs. Purpose-bred beagles were vaccinated at 8-10 weeks of age and each received three to four doses of the recombinant protein formulated with an aluminum-based adjuvant for ASO2 (GlaxoSmithKline). (A) Anti-Na-ASP-1 IgE, (B) anti-Ac-MTP-1 IgG2, (C) anti-TTR IgE. Figure 6B was modified from a figure published in Hotez et al. (2002).

\section{Acknowledgments}

The authors are grateful for the financial support of the Human Hookworm Vaccine Initiative of the Bill and Melinda Gates Foundation and the Sabin Vaccine Institute, a Clinical Research Grant from the March of Dimes Birth Defects Foundation, Grants AI-32726 and FI- from the $\mathrm{NIH}$, and Parasitology Grant \#98-674 of the China Medical Board of New York. We wish to thank Ms. Esperanza Diaz del Castillo for her assistance in the preparation of 
the manuscript, and Mr. Jordan Plieskatt for his assistance in the preparation of the figures.

\section{References}

Albonico et al., 1999. M. Albonico, D. W. Crompton and L. Savioli, Control strategies for human intestinal nematode infections. Adv. Parasitol. 42 (1999), pp. 277-341.

Albonico et al., 1995. M. Albonico, P. G. Smith, E. Ercole, A. Hall, H. M. Chwaya, K. S. Alawi and L. Savioli, Rate of reinfection with intestinal nematodes after treatment of children with mebendazole or albendazole in a highly endemic area. Trans. R. Soc. Trop. Med. Hyg. 89 (1995), pp. 538-541.

Beasley et al., 2002. M. Beasley, S. Brooker, M. Ndinaromtan, E. M. Madjiouroum, M. Baboguel, E. Djenguinabe and D. A. Bundy, First nationwide survey of the health of schoolchildren in Chad. Trop. Med. Int. Health 7 (2002), pp. 625-630.

Behnke et al., 2000. J. M. Behnke, D. De Clercq, M. Sacko, F. S. Gilbert, D. B. Ouattara and J. Vercruysse, The epidemiology of human hookworm infections in the southern region of Mali. Trop. Med. Int. Health 5 (2000), pp. 343-354.

Behnke and Pritchard, 1987. J. M. Behnke and D. I. Pritchard, Necator americanus in neonatally infected hamsters. The time course of infection and antibody response to the surface antigens of L4 and adult worms. Trans. R. Soc. Trop. Med. Hyg. 81 (1987), pp. 967-972.

Bethony et al., 2002. J. Bethony, J. Z. Chen, S. X. Lin, S. H. Xiao, B. Zhan, S. W. Li, H. C. Xue, F. Y. Xing, D. Humphries, Y. Wang, G. Chen, V. Foster, J. M. Hawdon and P. J. Hotez, Emerging patterns of hookworm infection: influence of aging on the intensity of Necator infection in Hainan Province, People's Republic of China. Clin. Infect. Dis. 35 (2002), pp. 1336-1344.

Birkett et al., 2002. A. Birkett, K. Lyons, A. Schmidt, D. Boyd, G. A. Oliveira, A. Siddique, R. Nussenzweig, J. M. Calvo-Calle and E. Nardin, A modified hepatitis B virus core particle containing multiple epitopes of the Plasmodium falciparum circumsporozoite protein provides a highly immunogenic malaria vaccine in preclinical analyses in rodent and primate hosts. Infect. Immun. 70 (2002), pp. 6860-6870.

Bloch and Rivera, 1977. M. Bloch and H. Rivera, La enfermedad Ancylostomiasica. Magnitud del problema. El por que lo ignoramus. Rev. Inst. Invest. Med. 6 (1977), pp. 105-130.

Bojang et al., 2001. K. A. Bojang, P. J. Milligan, M. Pinder, L. Vigneron, A. Alloueche, K. E. Kester, W. R. Ballow, D. J. Conway, W. H. Reece, P. Gothard, L. Yamuah, M. Delchambre, G. Voss, B. M. Greenwood, A. Hill, K. P. McAdam, N. Tornieporth, J. D. Cohen, T. Doherty and S. RTS, Malaria Vaccine Trial Team. Efficacy of RTS, S/ASO2 malaria vaccine against Plasmodium falciparum infection in semi-immune adult men in The Gambia: a randomized trial. Lancet 358 (2001), pp. 1927-1934.

Borkow and Bentwich, 2000. G. Borkow and Z. Bentwich, Eradication of helminthic infections may be essential for successful vaccination against HIV and tuberculosis. Bull. WHO 78 (2000), pp. $1368-1369$

Borkow et al., 2000. G. Borkow, Q. Leng, Z. Weisman, M. Stein, N. Galai, A. Kalinkovich and Z. Bentwich, Chronic immune activation associated with intestinal helminth infections results in impaired signal transduction and anergy. J. Clin. Invest. 106 (2000), pp. 1053-1060.

Borkow et al., 2001. G. Borkow, Z. Weisman, Q. Leng, M. Stein, A. Kalinkovich, D. Wolday and Z. Bentwich, Helminths, human immunodeficiency virus and tuberculosis. Scand. J. Infect. Dis. 33 (2001), pp. 568-571.

Bradley et al., 1993. M. Bradley, S. K. Chandiwana and D. A. Bundy, The epidemiology and control of hookworm infection in the Burma Valley area of Zimbabwe. Trans. R. Soc. Trop. Med. Hyg. 87 (1993), pp. 145-147.

Brinkworth et al., 2000. R. I. Brinkworth, S. A. Harrop, P. Prociv and P. J. Brindley, Host specificity in blood feeding parasites: a defin- ing contribution by haemoglobin-degrading enzymes?. Int. J. Parasitol. 30 (2000), pp. 785-790.

Brinkworth et al., 2001. R. I. Brinkworth, P. Prociv, A. Loukas and P. J. Brindley, Hemoglobin-degrading aspartic proteases of blood-feeding parasites: substrate specificity revealed by homology models. J. Biol. Chem. 276 (2001), pp. 38844-38851.

Broder et al., 2002. S. Broder, S. L. Hoffman and P. J. Hotez, Cures for the third world's problems: the application of genomics to the diseases plaguing the developing world may have huge medical and economic benefits for those countries and might even prevent armed conflict. EMBO Rep. 3 (2002), pp. 806-812.

Brooker et al., 2000a. S. Brooker, E. A. Miguel, S. Moulin, A. I. Luoba, D. A. P. Bundy and M. Kremer, Epidemiology of single and multiple species helminth infections among schoolchildren in Busia district, Kenya. East Afr. Med. J. 77 (2000), pp. 157-161.

Brooker et al., 2000b. S. Brooker, M. Rowlands, L. Haller, L. Savioli and D. A. P. Bundy, Towards an atlas of human helminth infection in sub-Saharan Africa: the use of geographical information systems (GIS). Parasitol. Today 16 (2000), pp. 303-307.

Bundy, 1990. D. A. P. Bundy, Is the hookworm just another geohelminth?. In: G. A. Schad and K. S. Warren, Editors, Hookworm Disease, Current Status and New Directions, Taylor \& Francis, London (1990), pp. 147-164.

Bundy et al., 1995. D. A. Bundy, M. S. Chan and L. Savioli, Hookworm infection in pregnancy. Trans. R. Soc. Trop. Med. Hyg. 89 (1995), pp. 521-522.

Bungiro et al., 2001. R. D. Bungiro, Jr., J. Greene, E. Kruglov and M. Cappello, Mitigation of hookworm disease by immunization with soluble extracts of Ancylostoma ceylanicum. J. Infect. Dis. 1839 (2001), pp. 1380-1387.

Cappello et al., 1996. M. Cappello, J. M. Hawdon, B. F. Jones, P. W. Kennedy and P. J. Hotez, Cloning and expression of Ancylostoma caninum anticoagulant peptide (AcAP). Mol. Biochem. Parasitol. 80 (1996), pp. 113-117.

Cappello et al., 1995. M. Cappello, G. P. Vlasuk, P. W. Bergum, S. Huang and P. J. Hotez, Ancylostoma caninum anticoagulant peptide (AcAP): a novel hookworm derived inhibitor of human coagulation factor Xa. Proc. Natl Acad. Sci. U. S. A. 92 (1995), pp. 6152-6156.

Chandler, 1932. A. C. Chandler, Susceptibility and resistance to helminthic infections. J. Parasitol. 3 (1932), pp. 135-152.

Chandler, 1936. A. C. Chandler, Studies on the nature of immunity to intestinal helminths. III. Renewal of growth and egg production in Nippostrongylus after transfer from immune to non-immune rats. Am. J. Hyg. 23 (1936), pp. 36-54.

Conder and Campbell, 1995. G. A. Conder and W. C. Campbell, Chemotherapy of nematode infections of veterinary importance, with special reference to drug resistance. Adv. Parasitol. 35 (1995), pp. $1-84$.

Culley et al., 2000. F. J. Culley, A. Brown, D. M. Conroy, I. Sabroe, D. I. Pritchard and T. J. Williams, Eotaxin is specifically cleaved by hookworm metalloproteases preventing its action in vitro and in vivo. J. Immunol. 165 (2000), pp. 6447-6453.

De Clercq et al., 1997. D. De Clercq, M. Sacko, J. Behnke, F. Gilbert, P. Dorny and J. Vercruysse, Failure of mebendazole in treatment of human hookworm infections in the southern region of Mali. Am. J. Trop. Med. Hyg. 57 (1997), pp. 25-30.

De Maere et al., 2002. V. De Maere, I. Vercauteren, H. Saverwyns, E. Claerebout, G. Berx and J. Vercruysse, Identification of potential protective antigens of Ostertagia ostertagi with local antibody probes. Parasitology 125 (2002), pp. 383-391.

Doherty et al., 1999. J. F. Doherty, M. Pinder, N. Tornieporth, C. Carton, L. Vigneron, P. Milligan, W. R. Ballou, C. A. Holland, K. E. Kester, G. Voss, P. Momin, B. M. Greenwood, K. P. McAdam and J. Cohen, A phase I safety and immunogenicity trial with the candidate malaria vaccine RTS, S/SBAS2 in semi-immune adults in the Gambia. Am. J. Trop. Med. Hyg. 61 (1999), pp. 865-868.

Dreyfuss et al., 2000. M. L. Dreyfuss, R. J. Stoltzfus, J. B. Shrestha, E. K. Pradham, S. C. LeClerq, S. K. Khatry, S. R. Shrestha, J. Katz, M. Albonico and K. P. West, Jr., Hookworms, malaria and vitamin A de- 
ficiency contribute to anemia and iron deficiency among pregnant women in the plains of Nepal. J. Nutr. 130 (2000), pp. 2527-2536.

Foster, 1935. A. O. Foster, The immunity of dogs to Ancylostoma caninum. Am. J. Hyg. 22 (1935), pp. 65-105.

Gandhi et al., 2001. N. S. Gandhi, J. Z. Chen, K. Koshnood, F. Y. Xing, S. W. Li, Y. R. Liu, Z. Bin, X. Haechou, T. Chong-Jin, W. Yan, W. Wensen, H. Dungxing, C. Chong, X. Shuhua, J. M. Hawdon and P. J. Hotez, Epidemiology of Necator americanus hookworm infections in Xiulongkan Village, Hainan Province, China: high prevalence and intensity among middle-aged and elderly residents. J. Parasitol. 87 (2001), pp. 739-743.

Geldhof et al., 2003. P. Geldhof, I. Vercauteren, K. Gevaert, A. Staes, D. P. Knox, J. Vandekerckhove, J. Vercruysse and E. Claerebout, Activation-associated secreted proteins are the most abundant antigens in a host protective fraction from Ostertagia ostertagi. Mol. Biochem. Parasitol. 128 (2003), pp. 111-114.

Ghosh et al., 1996. K. Ghosh, J. M. Hawdon and P. J. Hotez, Vaccination with alum-precipitated ASP-1 protects mice against challenge infections with infective hookworm (Ancylostoma caninum) larvae. J. Infect. Dis. 174 (1996), pp. 1380-1383.

Ghosh and Hotez, 1999. K. Ghosh and P. J. Hotez, Antibody-dependent reductions in mouse hookworm burden after vaccination with Ancylostoma caninum secreted protein 1. J. Infect. Dis. 180 (1999), pp. 1674-1678.

Griffiths and Pritchard, 1994. G. Griffiths and D. I. Pritchard, Vaccination against gastrointestinal nematodes of sheep using purified secretory acetylcholinesterase from Trichostrongylus colubriformis an initial pilot study. Parasite Immunol. 16 (1994), pp. 507-510.

Harrop et al., 1996. S. A. Harrop, P. Prociv and P. J. Brindley, Acasp, a gene encoding a cathepsin D-like aspartic protease from the hookworm Ancylostoma caninum. Biochem. Biophys. Res. Commun. 227 (1996), pp. 294-302.

Harrop et al., 1995. S. A. Harrop, N. Sawangjaroen, P. Prociv and P. J. Brindley, Characterization and localization of cathepsin B proteinases expressed by adult Ancylostoma caninum hookworms. Mol. Biochem. Parasitol. 71 (1995), pp. 163-171.

Haswell-Elkins et al., 1988. M. R. Haswell-Elkins, D. B. Elkins, K. Manjula, E. Michael and R. M. Anderson, An investigation of hookworm infection and reinfection following mass anthelmintic treatment in the South Indian fishing community of Vairavankuppam. Parasitology 96 (1988), pp. 565-577.

Hawdon and Hotez, 1996. J. M. Hawdon and P. J. Hotez, Hookworm: developmental biology of the infectious process. Curr. Opin. Genet. Dev. 6 (1996), pp. 618-623.

Hawdon et al., 1996. J. M. Hawdon, B. F. Jones, D. Hoffman and P. J. Hotez, Cloning and expression of Ancylostoma secreted protein: a polypeptide associated with the transition to parasitism by infective hookworm larvae. J. Biol. Chem. 271 (1996), pp. 6672-6678.

Hawdon et al., 1995. J. M. Hawdon, B. Jones, M. Perregaux and P. J. Hotez, Ancylostoma caninum: resumption of hookworm larval feeding coincides with metalloprotease release. Exp. Parasitol. 80 (1995), pp. 205-211.

Hawdon et al., 1999. J. M. Hawdon, S. Narasimhan and P. J. Hotez, Ancylostoma secreted protein 2: cloning and characterization of a second member of a family of nematode secreted proteins from Ancylostoma caninum. Mol. Biochem. Parasitol. 99 (1999), pp. 149-165.

Henriksen et al., 2001. A. Henriksen, T. P. King, O. Mirza, R. I. Monsalve, K. Meno, H. Ipsen, J. N. Larsen, M. Gajhede and M. D. Spangfort, Major venom allergen of yellow jackets, Ves V5: structural characterization of a pathogenesis-related protein superfamily. Proteins 45 (2001), pp. 438-448.

Hotez, 1989. P. J. Hotez, Hookworm disease in children. Pediatr. Infect. Dis. J. 8 (1989), pp. 516-520.

Hotez, 2000. P. J. Hotez, Pediatric geohelminth infections: trichuriasis, ascariasis, and hookworm infections. Semin. Pediatr. Infect. Dis. 11 (2000), pp. 236-244.

Hotez, 2001. P. J. Hotez, Vaccines as instruments of foreign policy. EMBO Rep. 2 (2001), pp. 862-868.

Hotez, 2002. P. J. Hotez, China's hookworms. China Q. 172 (2002), pp. 1029-1041.
Hotez et al., 2002. P. J. Hotez, J. Ashcom, B. Zhan, J. Bethony, A. Williamson, J. M. Hawdon, J. J. Feng, A. Dobardzic, I. Rizo, J. Bolden, J. Qun, Y. Wang, R. Dobardzic, M. Crowell, B. Datu, S. Debose, A. Delaney, D. Dragonovski, J. Yang, A. Loukas, P. K. Russell, B. C. Zook and W. Brandt, Effect of recombinant fusion protein vaccinations on Ancylostoma caninum adult hookworm habitat selection in the canine intestine. J. Parasitol. 88 (2002), pp. 684-690.

Hotez et al., 1997. P. J. Hotez, Z. Feng, L. Q. Xu, M. G. Chen, S. H. Xiao, S. X. Liu, D. Blair, D. P. McManus and G. M. Davis, Emerging and reemerging helminthiases and the public health of China. Emerg. Infect. Dis. 3 (1997), pp. 303-310.

Hotez et al., 1999. P. Hotez, K. Ghosh, J. M. Hawdon, S. Narasimhan, B. Jones, S. H. Xiao, S. Liu, B. Zhan, H. C. Xue, H. N. Ren, H. Wang and R. Koski, Experimental approaches to the development of a recombinant hookworm vaccine. Immunol. Rev. 171 (1999), pp. 163-171.

Hotez et al., 1996. P. J. Hotez, J. M. Hawdon, B. F. Jones, K. Ghosh, M. Cappello, F. Volvovitz and S. -H. Xiao, Molecular approaches to hookworm vaccines. Pediatr. Res. 40 (1996), pp. 515-521.

Hotez et al., in press. Hotez, P. J., Zhan, B., Loukas, A., Bethony, J. M., Ashcom, J., Ghosh, K., Hawdon, J. M., Brandt, W., Russell, P. K. Vaccines against human hookworm disease. In: Levine, M. M., Kaper, J. B., Rappuoli, R., Liu, M., Good, M. (Eds. ), New Generation Vaccines, third ed. Marcel Dekker, Inc, in press.

Hotez et al., 2002. P. J. Hotez, B. Zhan, R. Qun, J. Bethony, J. M. Hawdon, H. Young, S. Simmens, R. Hitzelberg and B. C. Zook, Natural history of primary canine hookworm infections following three different oral doses of third-stage infective larvae of Ancylostoma caninum. Comp. Parasitol. 69 (2002), pp. 72-80.

Humphries et al., 1997. D. L. Humphries, L. S. Stephenson, E. J. Pearce, P. H. The, H. T. Dan and L. T. Khanh, The use of human faeces for fertilizer is associated with increased intensity of hookworm infection in Vietnamese women. Trans. R. Soc. Trop. Med. Hyg. 91 (1997), pp. 518-520.

Jones and Hotez, 2001. B. F. Jones and P. J. Hotez, Molecular cloning and characterization of Ac-MEP-1 a developmentally regulated gut luminal metalloendopeptidase from adult Ancylostoma caninum hookworm. Mol. Biochem. Parasitol. 119 (2001), pp. 107-116.

Kerr, 1936. K. B. Kerr, Studies on acquired immunity to the dog Ancylostoma caninum. Am. J. Hyg. 23 (1936), pp. 381-406.

Knox, 2000. D. P. Knox, Development of vaccines against gastrointestinal nematodes. Parasitology 120 (2000), pp. S43-S61.

Knox and Smith, 2001. D. P. Knox and W. D. Smith, Vaccination against gastrointestinal nematode parasites of ruminants using gut-expressed antigens. Vet. Parasitol. 100 (2001), pp. 21-32.

Kooyman et al., 2000. F. N. J. Kooyman, H. D. F. H. Schallig, M. A. W. van Leeuwen, A. Mackellar, J. F. Huntley, A. W. C. A. Cornelissen and L. Vervelde, Protection in lambs vaccinated with Haemonchus contortus antigens is age related, and correlates with IgE rather than IgG1 antibody. Parasite Immunol. 22 (2000), pp. 13-20.

Labiano-Abello et al., 1999. N. Labiano-Abello, J. Canese, J. M. Velazquez, J. M. Hawdon, M. L. Wilson and P. J. Hote, Epidemiology of hookworm infection in Itagua, Paraguay: a cross sectional study. Mem. Inst. Oswaldo Cruz 94 (1999), pp. 583-586.

Liu et al., 1999. C. G. Liu, X. R. Zhang, D. C. Qiu, S. H. Xiao, P. J. Hotez, D. F. Zheng, H. C. Xue, H. L. Zhen, M. G. Li, H. N. Ren, B. Zhan, J. Hawdon and Z. Feng, Epidemiology of human hookworm infections among adult rural villagers in Heijiang and Santai Counties, Sichuan Province, China. Acta Trop. 73 (1999), pp. 255-265.

Liu et al., 2000. S. Liu, K. Ghosh, B. Zhan, Q. Shan, M. G. Thompson, J. Hawdon, S. H. Xiao, R. A. Koski and P. J. Hotez, Hookworm burden reductions in BALB/c mice vaccinated with Ancylostoma secreted protein 1 (ASP-1) from Ancylostoma duodenale, A. caninum and Necator americanus. Vaccine 18 (2000), pp. 1096-1102.

Loukas et al., 2000. A. Loukas, A. J. Dowd, P. Prociv and P. J. Brindley, Purification of a diagnostic, secreted cysteine protease-like protein from the hookworm Ancylostoma caninum. Parasitol. Int. 49 (2000), pp. 327-333.

Lwambo et al., 2000. N. J. Lwambo, S. Brooker, J. E. Siza, D. A. Bundy and H. Guyatt, Age patterns in stunting and anemia in African 
schoolchildren: a cross-sectional study in Tanzania. Eur. J. Clin. Nutr. 54 (2000), pp. 36-40.

Lwambo et al., 1991. N. J. Lwambo, D. A. Bundy and G. F. Medley, A new approach to morbidity risk assessment in hookworm endemic communities. Epidemiol. Infect. 108 (1991), pp. 469-481.

Lwambo et al., 1999. N. J. Lwambo, J. E. Siza, S. Brooker, D. A. Bundy and H. Guyatt, Patterns of concurrent hookworm infection and schistosomiasis in Tanzania. Trans. R. Soc. Trop. Med. Hyg. 93 (1999), pp. 497-502.

Maxwell et al., 1987. C. Maxwell, R. Hussain, T. B. Nutman, R. W. Poindexter, M. D. Little, G. A. Schad and E. A. Ottesen, The clinical and immunologic responses of normal human volunteers to low dose hookworm (Necator americanus) infection. Am. J. Trop. Med. Hyg. 37 (1987), pp. 126-134.

McCoy, 1931. O. R. McCoy, Immunity reactions of the dog against hookworm (Ancylostoma caninum) under conditions of repeated infection. Am. J. Hyg. 14 (1931), pp. 268-303.

McKeand, 2000. J. B. McKeand, Vaccine development and diagnostics of Dictyocaulus viviparous. Parasitology 120 (2000), pp. S17-S23.

Miller, 1971. T. A. Miller, Vaccination against the canine hookworm diseases. Adv. Parasitol. 9 (1971), pp. 153-183.

Miller, 1978. T. A. Miller, Industrial development and field use of the canine hookworm vaccine. Adv. Parasitol. 16 (1978), pp. 333-342.

Miller, 1987. T. A. Miller, Immune responses in parasitic infections: immunology, immunopathology and immunoprophylaxis. In: E. J. L. Soulsby, Editor, Nematodes vol. I, CRC Press, Boca Raton, FL (1987).

Moyle et al., 1994. M. Moyle, D. L. Foster, D. E. McGrath, S. M. Brown, Y. Laroche, J. De Meutters, P. Stanssens, C. A. Bogowitz, V. A. Fried, J. A. Ely, H. R. Soule and G. P. Vlasuk, A hookworm glycoprotein that inhibits neutrophil function is a ligand of the integrin CD11b/CD18. J. Biol. Chem. 26913 (1994), pp. 10008-10015.

Murray and Lopez, 1996. C. J. L. Murray and A. D. Lopez, The Global Burden of Disease, Global Burden of Disease and Injury Series. , World Health Organization, Geneva (1996).

Otto, 1940. G. F. Otto, A serum antibody in dogs actively immunized against the hookworm Ancylostoma caninum. Am. J. Hyg. $31 \mathrm{D}$ (1940), pp. 23-27.

Otto, 1941. G. F. Otto, Further observations on the immunity induced in dogs by repeated infection with the hookworm Ancylostoma caninum. Am. J. Hyg. 33 D (1941), pp. 39-57.

Otto and Kerr, 1939. G. F. Otto and K. B. Kerr, The immunization of dogs against hookworm Ancylostoma caninum, by subcutaneous injection of graded doses of larvae. Am. J. Hyg. 29 D (1939), pp. $25-45$.

Palmer and Bundy, 1995. D. R. Palmer and D. A. P. Bundy, Epidemiology of human hookworm and Ascaris lumbricoides infestations in rural Gambia. East Afr. Med. J. 72 (1995), pp. 527-530.

Partnership for Child Development, 1998. Partnership for Child Development, The health and nutritional status of schoolchildren in Africa: evidence from school-based health programs in Ghana and Tanzania. Trans. R. Soc. Trop. Med. Hyg. 92 (1998), pp. 254-261.

Pritchard et al., 1995. D. I. Pritchard, R. J. Quinnell and E. A. Walsh, Immunity in humans to Necator americanus: IgE, parasite weight and fecundity. Parasite Immunol. 17 (1995), pp. 71-75.

Pritchard and Walsh, 1995. D. I. Pritchard and E. A. Walsh, The specificity of the human IgE response to Necator americanus. Parasite Immunol. 17 (1995), pp. 605-607.

Quinnell et al., 1993. R. J. Quinnell, A. F. G. Slater, P. J. Tighe, E. A. Walsh, A. E. Keymer and D. I. Pritchard, Reinfection with hookworm after chemotherapy in Papua New Guinea. Parasitology 106 (1993), pp. 379-385.

Quinnell et al., 1995. R. J. Quinnell, M. E. Woolhouse, E. A. Walsh and D. I. Pritchard, Immunoepidemiology of human necatoriasis: correlations between antibody responses and parasite burdens. Parasite Immunol. 17 (1995), pp. 313-318.

Sakti et al., 1999. H. Sakti, C. Nokes, W. S. Hertanto, S. Hendratno, A. Hall, D. A. Bundy and Satoto, Evidence for an association between hookworm infection and cognitive function in Indonesian school children. Trop. Med. Int. Health 4 (1999), pp. 322-334.
Sarles, 1938. M. P. Sarles, The in vitro action of immune serum on the nematode Nippostrongylus muris. J. Infect. Dis. 62 (1938), pp. 337-348.

Schallig et al., 1997a. H. D. F. H. Schallig, M. A. W. van Leeuwen and A. W. C. A. Cornelissen, Protective immunity induced by vaccination with two Haemonchus contortus excretory secretory proteins in sheep. Parasite Immunol. 19 (1997), pp. 447-453.

Schallig et al., 1997b. H. D. F. H. Schallig, M. A. W. van Leeuwen and W. M. L. Hendrikx, Immune responses of sheep to excretory/secretory products of adult Haemonchus contortus. Parasitology 108 (1997), pp. 351-357.

Schallig et al., 1997c. H. D. Schallig, M. A. van Leeuwen, B. E. Verstrepen and A. W. Cornelissen, Molecular characterization and expression of two putative protective excretory secretory proteins of Haemonchus contortus. Mol. Biochem. Parasitol. 88 (1997), pp. 203-213.

Sharp et al., 1992. Sharp, P. J., Wagland, B. M., Cobon, G. S., 1992. Nematode vaccine. International patent application number PCT/ AU92/00041. International Publication Number WO92/13889 and 13890.

Sharp and Wagland, 1998. Sharp, P. J., Wagland, B. M., March 31, 1998. Nematode vaccine. United States Patent Number 5, 734, 035.

Sheldon and Groover, 1942. A. J. Sheldon and M. E. Groover, Jr., An experimental approach to the problem of acquired immunity in human hookworm (Necator americanus) infections. Am. J. Hyg. 36 (1942), pp. 183-186.

Smilie and Augustine, 1926. W. G. Smilie and D. L. Augustine, Hookworm infestation: the effect of varying intensities on the physical condition of school children. Am. J. Dis. Child. 31 (1926), pp. 151-168.

Stanssens et al., 1996. P. Stanssens, P. W. Bergum, Y. Gansemans, L. Jespers, Y. Laroche, S. Huang, S. Maki, J. Messens, M. Lauwereys, M. Cappello, P. J. Hotez, I. Lasters and G. P. Vlasuk, Anticoagulant repertoire of the hookworm Ancylostoma caninum. Proc. Natl Acad. Sci. U. S. A. 93 (1996), pp. 2149-2154.

Stephenson et al., 1989. L. S. Stephenson, M. C. Latham, K. M. Kurz, S. N. Kinoti and H. Brigham, Treatment with a single dose of albendazole improves growth of Kenyan schoolchildren with hookworm, Trichuris trichiura, and Ascaris lumbricoides infection. Am. J. Trop. Med. Hyg. 41 (1989), pp. 78-87.

Stoll, 1962. N. R. Stoll, On endemic hookworm, where do we stand today?. Exp. Parasitol. 12 (1962), pp. 241-248.

Stoltzfus et al., 1997a. R. J. Stoltzfus, H. M. Chwaya, J. M. Tielsch, K. J. Schulze, M. Albonico and L. Savioli, Epidemiology of iron deficiency anemia in Zanzibari schoolchildren: the importance of hookworms. Am. J. Clin. Nutr. 65 (1997), pp. 153-159.

Stoltzfus et al., 1997b. R. J. Stoltzfus, M. L. Dreyfuss, H. M. Chwaya and M. Albonico, Hookworm control as a strategy to prevent iron deficiency. Nutr. Rev. 55 (1997), pp. 223-232.

Stoltzfus et al., 2001. R. J. Stoltzfus, J. D. Kvalsvig, H. M. Chwaya, A. Montresor, M. Albonico, J. M. Tielsch, L. Savioli and T. E. Pollit, Effects of iron supplementation and anthlemintic treatment on motor and language development of preschool children in Zanzibar: double blind, placebo controlled study. Br. Med. J. 323 (2001), pp. 1389-1393.

Taliaferro and Sarles, 1939. W. H. Taliaferro and M. P. Sarles, The cellular reactions in the skin, lungs and intestine of normal and immune rats after infection with Nippostrongylus muris. J. Infect. Dis. 64 (1939), pp. 157-192.

Tawe et al., 2000. W. Tawe, E. Pearlman, T. R. Unnasch and S. Lustigman, Angiogenic activity of Onchocerca volvulus recombinant proteins similar to vespid venom antigen 5. Mol. Biochem. Parasitol. 109 (2000), pp. 91-99.

Thorson, 1956. R. E. Thorson, The stimulation of acquired immunity in dogs by the injection of extracts of the oesophagus of adult hookworms. J. Parasitol. 42 (1956), pp. 501-504.

Wang et al., 1999. Y. Wang, G. G. Shen, W. T. Wu, S. H. Xiao, P. J. Hotez, Q. Y. Li, H. C. Xue, X. M. Yi, X. M. Liu, B. Zhan, J. M. Hawdon, L. Chou, H. Ji, C. M. Hu and Z. Feng, Epidemiology of human ancylostomiasis among rural villagers in Nanlin County (Zhong- 
zhou Village), Anhui Province, China. Age-associated prevalence, intensity, and hookworm species identification. Southeast Asian J. Trop. Med. Public Health 30 (1999), pp. 692-697.

Williamson et al., 2002. A. L. Williamson, P. J. Brindley, G. Abbenante, P. Prociv, C. Berry, K. Girdwood, D. I. Pritchard, D. P. Fairlie, P. J. Hotez, J. P. Dalton and A. Loukas, Cleavage of hemoglobin by hookworm cathepsin D aspartic proteases and its potential contribution to host-specificity. FASEB J. 16 (2002), pp. 1458-1460.

Williamson et al., 2003a. A. L. Williamson, P. J. Brindley, G. Abbenante, P. Prociv, C. Berry, K. Girdwood, D. I. Pritchard, D. P. Fairlie, P. J. Hotez, B. Zhan and A. Loukas, Hookworm aspartic protease, Na-APR-2 cleaves human hemoglobin and serum proteins in a host-specific fashion. J. Infect. Dis. 187 (2003), pp. 484-494.

Williamson et al., 2003b. A. L. Williamson, P. J. Brindley, P. J. Hotez and A. Loukas, Hookworm aspartic proteases cleave serum albumin and fibrinogen in a host specific manner. Parasitology 126 (2003), pp. 179-185.

Wolday et al., 2002. D. Wolday, S. Mayaan, Z. G. Mariam, N. Berhe, T. Seboxa, S. Britton, N. Galai, A. Landay and Z. Bentwich, Treatment of intestinal worms is associated with decreased HIV plasma viral load. J. Acquir. Immune Defic. Syndr. 31 (2002), pp. 56-62.

WHO, 2000. World Health Organization, 2000. Communicable diseases: control of schistosomiasis and soil-transmitted helminth infections (report by the Secretariat). Executive Board, 107th Session, 27 October.

WHO, 2002. WHO, 2002. The World Health report 2002, reducing risks, promoting health life.

Xue et al., in press. Xue, J., Liu, S., Qiang, H. Q., Ren, H. N., Li, T. H., Xue, H. C., Hotez, P. J., Xiao, S. H. Necator americanus: maintenance through one hundred generations in golden hamsters (Mesocricetus auratus). I. Host sex-associated differences in hookworm burden and fecundity. Exp. Parasitol., in press.

Zhan et al., 2002b. B. Zhan, M. Badamchian, M. H. Bo, J. Ashcom, J. J. Feng, J. Hawdon, S. H. Xiao and P. J. Hotez, Molecular cloning and purification of Ac-TMP a developmentally regulated putative tissue inhibitor of metalloprotease released in relative abundance by adult Ancylostoma hookworms. Am. J. Trop. Med. Hyg. 66 3 (2002), pp. 238-244.

Zhan et al., 1999. B. Zhan, J. M. Hawdon, Q. Shan, H. N. Ren, H. Q. Qiang, W. Hu, S. H. Xiao, T. H. Li, X. Gong, Z. Feng and P. J. Hotez, Ancylostoma secreted protein-1 (ASP-1) homologues from human hookworms. Mol. Biochem. Parasitol. 98 (1999), pp. 143-149.

Zhan et al., 2002a. B. Zhan, P. J. Hotez, Y. Wang and J. M. Hawdon, A developmentally regulated metalloprotease secreted by host-stimulated Ancylostoma caninum third-stage infective larvae is a member of the astacin family of proteases. Mol. Biochem. Parasitol. 120 (2002), pp. 291-296.

Zhan et al., in press. Zhan, B., Liu, Y. Y., Badamchian, M., Williamson, A., Feng, J. J., Loukas, A., Hawdon, J. M., Hotez, P. J. Molecular characterization of the Ancylostoma secreted protein (ASP) family from the adult stage of Ancylostoma caninum. Int. J. Parasitol., in press.

Zhan et al., 2000. L. L. Zhan, B. X. Zhang, H. Tao, S. H. Xiao, P. Hotez, B. Zhan, Y. Z. Li, Y. Li, H. C. Xue, J. Hawdon, H. Yu, H. Z. Wang and Z. Feng, Epidemiology of human geohelminth infections, (ascariasis, trichuriasis and necatoriasis) in Lushui and Puer Counties, Yunnan Province, China. Southeast Asian J. Trop. Med. Public Health 31 (2000), pp. 448-453.

\section{Further Reading}

Hotez, P. J., Ashcom, J., Zhan, B., Bethony, J., Loukas, A., Hawdon, J., Wang, Y., Qun, J., Jones, K. C., Dobardzic, A., Dobardzic, R., Bolden, J., Essiet, I., Brandt, W., Russell, P. K., Zook, B. C., Howard, B., Chacon, M., 2003. Effect of vaccinatin with a recombinant fusion protein encoding an astacin-like metalloprotease (MTP-1) secreted by host-stimulated Ancylostoma caninum third-stage infective larvae. J. Parasitol. (in press). 